$24.5 \%$ of all respondents ( $21 \%$ of consultants) would provide information to agencies with a duty to investigate e.g. social work.

The second vignette describes a 38-year-old mildly depressed male out-patient recently separated from his wife. He has no previous history of violence but is described as angry, embittered and aggrieved. He describes often having thoughts (but denies plans) of stabbing his wife and new partner. He specifically states that his wife should not know of his attendance as he fears it may have some bearing on future custody issues. In response $9.4 \%$ of all respondents (5\% of consultants) considered warning the wife and partner or informing the police. All of these respondents suggest that they would first discuss the issue with their defence union or in the case of one consultant disclose information if the risk of enactment was judged to be high.

The results from our survey suggest that psychiatrists in the UK, generally do not 'warn' but are more likely to respect confidentiality. This is in contrast to the authors' contention that psychiatric practice has now altered towards warning third parties. If, as the authors' suggest. there is to be a change in the legal responsibility towards third parties, it may be that the majority of psychiatrists will be changing their practice in response to such, rather than pre-empting such changes.

RTrCHE, J. H., DICK, D. \& LINGHAM, R. (1994) Report of the Inquiry into the Care and Treatment of Christopher Clunis. London: HMSO.

AlleEN Blower, Staff Grade Psychiatrist, Hartfield Clinic, Dumbarton; and MARK COHEN, Senior Registrar in Psychiatry, State Hospital, Carstairs

\section{CPA: faith or fact}

The convergence of traditional cost saving and modern libertarian views, alongside the introduction of effective pharmacotherapy, allowed the 'asylum' closures. Highly desirable 'Care in the Community' was practised with enthusiasm. but without a concrete plan. A very few psychotically-driven violent patients forced the government to introduce the Care Programme Approach (CPA) to reassure society.

The CPA has generated much discussion, but little evidence of efficacy (Marshall, 1996) and even its most vocal supporters have concurred that it may generate an increased workload in the form of admissions and paperwork (Tyrer et al, 1995), while having no impact on suicide rates. Detractors have complained that the CPA is an unproved, unfunded, bureaucratic, unplanned and scape-goating exercise. Evidence also insists that it is not of value in detecting unmet needs or risk' in those who eventually kill themselves.

The general practitioners, who are the key to its success, have little interest in the CPA (Grace et al, 1996).

Much of the argument surrounding the CPA has been semantic in nature. For instance, though the CPA is targeted at the severely mentally ill, the ex-President of the College discouraged the use of this concept (Lacey \& Caldicott, 1996). Others have quibbled over the definitions of case management versus care management.

Some facts should be agreed upon. First, the CPA was introduced without due regard to implementation with the inevitable result of demotivating those needed for its enactment. Second, no extra resources have been allocated. Third, the face validity of CPA efficacy has not been complemented by convincing research evidence and cannot now be effectively studied given its statutory nature. Last, as allocation to the CPA is of necessity a subjective process and resources differ so wildly across the country, no meaningful audit of its use can be performed.

Ultimately the CPA is skewered by its own contradictions and those who beg an alternative must look to their own practice. Legislation cannot substitute for education.

Grace, J., Steels, M. \& Baruah, R. (1996) General practitioners' knowledge of and views on the care programme approach. Psychiatric Bulletin. 20. 643644.

LACEY, H. \& CALDICOTT, F. (1996) Less severe mental illness. Psychiatric Bulletin, 20, 496.

MARSHALL. M. (1996) Case management: a dubious practice. British Medical Journal, 312, 523-524.

TYRER, P., MORGan, J.. VAN HORN, E. et al (1995) A randomised controlled study of close monitoring of vulnerable psychiatric patients. Lancet, 346. 756-759.

ANDREW AL-ADWANI, Specialist Registrar, Doncaster Royal Infirmary; and D. W. NABI, Consultant Psychiatrist for the Elderly. Rotherham General Hospital

\section{Forgetfulness and blame}

I was recently consulted by a solicitor about a client of his who had been accused of, and charged with, theft from an elderly lady for who she, the accused, acted as a home care assistant. She was a middle aged lady of previous lily white reputation. The elderly lady had apparently told her son that money was missing from her pension and it had been stolen by her home care assistant. He reported this to the police and they kept the old person's house under observation. One day the care assistant involved was stopped by the police and was 
found to have $£ 15$ in her possession. She explained that this money had been given to her by the old lady to buy a cheap pair of slippers to replace the ones the old lady had worn out.

Some time later the police took a statement from the old lady in which she said she had not asked the helper to buy her new slippers and had not given her any money.

The prosecution supplied the defence with a letter from the old lady's family doctor stating that she was suffering from senile dementia, transient paranoid psychosis and depression. It went on to state that she was rather confused and deaf. However, the prosecution objected to the old lady being seen by a psychiatrist for the defence and sought to have her statement read out in court on the basis that she was too infirm to attend. In the event the case collapsed half way through and the accused was discharged.

When I thought I might become involved in the case as an expert witness I attempted to research the subject. I had come across such problems, but not involving the legal process. When some people become forgetful as a result of a dementing process or for other reasons they misplace things including money, or spend money and then forget they have done so. A proportion of these who could be described as having a personality trait more extropunitive than intropunitive will blame others for the perceived loss. They may accuse members of their family, friends, neighbours, or people coming into their home to help them. I have been accused on one occasion, but it is unusual for doctors to be suspected!

Such accusations cause considerable anxiety and distress, significantly increased if the legal system is involved. In the case briefly described the home care assistant may have been stealing money and the taking of money from the old lady to buy slippers was clearly unwise. The case did not proceed but the accused must have suffered a great deal of distress, all the worse if innocent, which was most likely.

In my attempt to research the subject, I failed to find anything about it except for the briefest mention. I would have thought the matter was of some importance and I would be most interested in hearing from any reader who knows of any work on this subject.

TONY WHITEHEAD, 2 Beacon Court, Greenways, Ovingdean, Brighton and Hove BN2 7AY

\section{Corrigenda}

Timms, P., Bulletin, 21, 573-575. Column 2, line 1 of the displayed text on p. 574 should read, 'It is inappropriate . . .
Interim statement on anti-dementia drugs, Bulletin, 21, 586-587. The date of the Kelly et al reference should read 1997. 